\title{
Intrusive Dental Injuries in Children: Manifestations and Management
}

\author{
${ }^{1}$ Krishan Gauba, ${ }^{2}$ Ashima Goyal, ${ }^{3}$ Sarabjot Kaur Bhatia
}

\begin{abstract}
Traumatic dental injuries occur frequently in children and young adults. Orofacial trauma that results in fractured, displaced or lost teeth can have significant negative functional, esthetic and psychological effect on child. Intrusive luxation of teeth results in axial impacts on maxillary and mandibular teeth and is considered one of the most severe types of dental trauma because of the risk for damage to the periodontal ligament, pulp and alveolar bone. To correctly diagnose the injury, efficiently determine the extent of injury to teeth and periodontium and supporting structures and to have a favorable outcome after management requires a systematic approach.
\end{abstract}

Keywords: Intrusive luxation, Children, Primary intruded teeth, Management of intruded teeth.

How to cite this article: Gauba K, Goyal A, Bhatia SK. Intrusive Dental Injuries in Children: Manifestations and Management. J Postgrad Med Edu Res 2014;48(2):53-62.

Source of support: Nil

Conflict of interest: None

\section{INTRODUCTION}

Dentoalveolar trauma is a common problem in children and represents a situation which demands immediate attention not only because of the injury which may be severe but also due to emotional distress to the child as well as to the parents. ${ }^{1}$ Literature review reports that $25 \%$ of school going children experience dental trauma at one or the other time with luxation injury being more common in the primary dentition and crown fracture being the commonly seen outcome in the permanent dentition. ${ }^{2}$ The greatest incidence of trauma to primary dentition occurs at 2 to 3 years when motor coordination is developing. The most common injury to permanent teeth occurs secondary to fall followed by traffic accidents, violence and sports. ${ }^{2}$ Dental injuries could have improved

\footnotetext{
${ }^{1,2}$ Professor, ${ }^{3}$ Assistant Professor

${ }^{1-3}$ Department of Pediatric Dentistry, Oral Health Sciences Centre, Postgraduate Institute of Medical Education and Research, Chandigarh, India
}

Corresponding Author: Sarabjot Kaur Bhatia, Assistant Professor, Oral Health Sciences Centre, Postgraduate Institute of Medical Education and Research, Chandigarh, India, Phone: 0172-2756838, e-mail: docsarab2005@rediffmail.com outcome if the public is aware of the first aid measures and tend to seek immediate treatment.

Intrusive luxation is defined as axial dislodgement of the tooth into alveolus. The injury represents an axial impact to the tooth where the energy released drive the tooth into the alveolar process resulting in extensive injury to the periodontium which gets torn and compressed and the neurovascular bundle supplying the pulp may get crushed or severed usually leading to a more or less extensive crown fracture. ${ }^{3}$

In primary teeth, intrusions account for 8 to $22 \%$ of all luxation injuries to anterior teeth. The teeth that are most frequently involved are central incisors. It is most commonly seen in the children aged 2 to 4 years. ${ }^{4}$ Primary teeth are more vulnerable to intrusive dental injuries because of large trabecular spaces which is an inherent characteristic of the developing bone tissue around primary teeth and the presence of root resorption. ${ }^{5}$

Intrusive luxation of permanent teeth is a rare trauma entity representing 0.5 to $2 \%$ of trauma affecting the permanent dentition. The age group most frequently experiencing intrusive injury to permanent teeth reported is 6 to 12 years with the most common etiologic factor being fall that results in axial impacts on maxillary and mandibular teeth. ${ }^{6}$ The injury caused to the periodontium has often been found to result in root resorption and marginal bone breakdown and the associated injury to the pulp may lead to pulpal necrosis and arrested root formation in cases of incomplete root formation. ${ }^{3}$ The rarity and complexities of intrusive luxation injury in permanent teeth has led to complicated healing scenario and an uncertain prognosis. In spite of these adverse sequelae, normal periodontal and pulp healing may occur after traumatic intrusion. ${ }^{7}$ The primary goal of the present article is to delineate an approach for the immediate and urgent care of intrusive dental injuries.

\section{GENERAL CONSIDERATIONS IN MANAGEMENT}

\section{History and Examination}

A thorough medical and dental history should be obtained together with details of how, when and where the accident occurred; these should be carefully recorded. The possibility of other injuries, including injuries to the head and facial region should be evaluated along with, as a large degree of force is required to severely intrude permanent incisor teeth. 


\section{Clinical Diagnosis}

The clinical diagnosis is based on a difference in the position/level of the incisal edges of the affected and unaffected tooth/teeth in an established dentition. The intruded tooth is usually immobile and may give high metallic sound on percussion. Sensibility tests will likely give negative results. ${ }^{8}$ The tooth may be completely buried in the alveolar process and be erroneously considered ex-articulated until a radiograph shows the intruded position. ${ }^{9}$ Palpation of the alveolar process often reveals the position of the displaced tooth. If a primary/permanent central incisor is completely intruded, it should be considered that the apex is most likely forced into the nasal cavity, resulting in bleeding from the nose. Examination of the floor of the nostril may reveal the protruding apex. ${ }^{10}$

\section{Radiographic Examination}

Several projections and angulations are routinely recommended but the final decision of radiographic investigation lies with the clinician depending on the type of intrusion. The radiograph in case of intrusive injury reveals differences in apical levels, alveolar fractures or signs of damage to adjacent teeth. The cementoenamel junction is located more apically in the intruded tooth compared to the adjacent noninjured tooth/teeth, at times even apical to the marginal bone level. The intruded tooth presents with missing or diminished periodontal space. ${ }^{8}$

In the primary dentition, radiographs can reveal the position of displaced teeth in relation to the permanent successors and the direction of dislocation. It is of great importance to determine whether the apex is dislocated facially or lingually, as the permanent successors can be directly involved. ${ }^{11}$ If the root is displaced through labial plate it will present as foreshortening of the intruded incisor in an

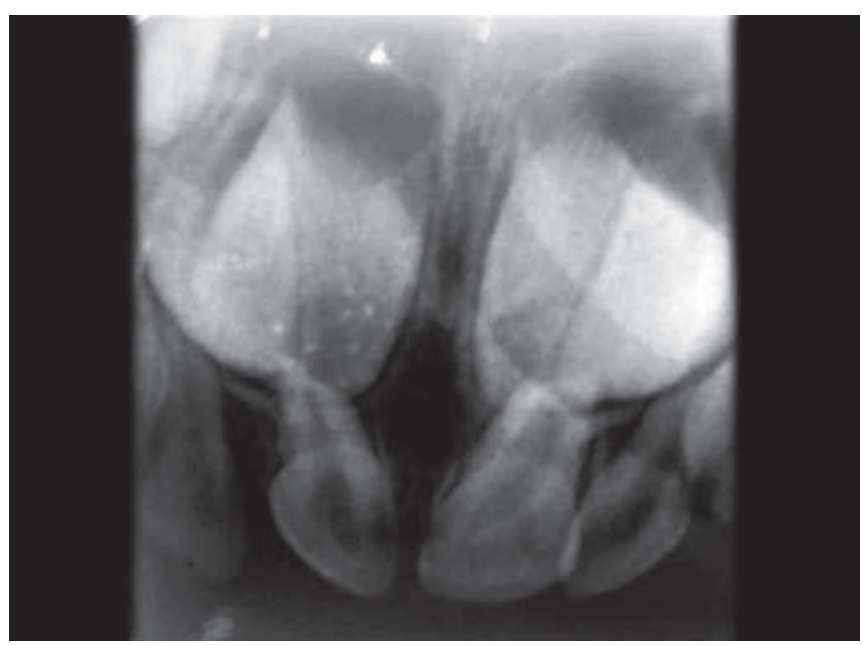

Fig. 1: Periapical radiograph showing shortening of primary tooth roots occlusal or periapical radiograph (Fig. 1). However, if the root is displaced palatally the primary tooth root appears elongated as compared to the adjacent tooth.

\section{Management of Intruded Primary Teeth}

A young child is often difficult to examine and treat because of the lack of cooperation and associated fear. Some of the important factors that influence management of such injuries are child's maturity and ability to cope with the emergency situation, root resorption, time period for shedding of the involved tooth, and the occlusion status. Many intruded primary teeth re-erupt to a functional position in due course of time. ${ }^{12}$

The developing permanent tooth bud is normally lingual to the roots of the primary central incisors. Because of the labial inclination of primary incisor roots, most roots of intruded primary incisors are forced toward the labial, often through the thin vestibular bone, as a result of the axial impact. Foreshortening of the intruded incisor in an occlusal radiographic examination normally confirms this direction of displacement. When intrusive displacement occurs such that the primary tooth remains labial to the developing permanent tooth, in such cases, re-eruption of the primary
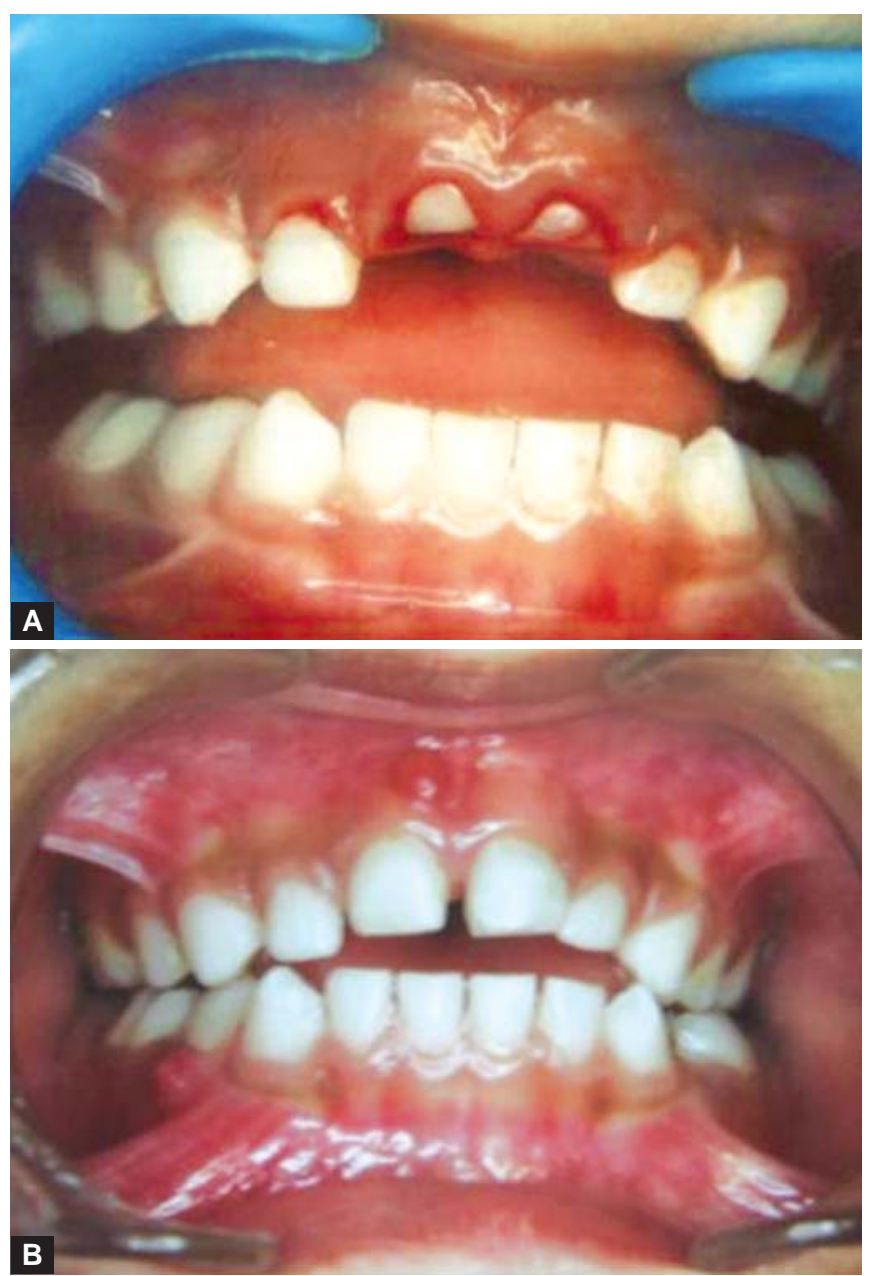

Figs 2A and B: (A) Intrusion of primary maxillary central incisors post-trauma in a 4 years old and (B) spontaneous re-eruption of the incisors after 4 months 
incisor is anticipated, which normally occurs within 2 to 3 months after the injury ${ }^{5,13}$ (Figs $2 \mathrm{~A}$ and B).

If the crown of the intruded primary tooth is dislocated labially, the root apex gets displaced lingually and encroaches on the developing permanent tooth bud. If a contact with the permanent tooth bud is suspected clinically and verified by a lateral anterior radiograph, the primary incisor should be removed. ${ }^{12}$ In cases in which intrusive forces displace the primary incisor root into the follicle zone, removal of the displaced tooth is essential to relieve pressure on the tissue within the follicle. ${ }^{14}$ When extracting the intruded primary incisor, extreme care must be taken during the procedure so as not to elicit any further injury to the permanent successor (Figs 3A to C).

Some factors may influence the re-eruption of intruded primary teeth. In children with abnormal oral habits like digit sucking or tongue thrusting habits, the pressure from these habits may prevent the affected tooth from re-erupting. Also, many teeth at times rotate as they get intruded so that when they re-erupt they are in traumatic occlusion. The treatment of intruded primary teeth is debatable, but the main concern always remains the prevention of damage to the succedane- ous teeth. In a retrospective study of 123 intruded primary teeth $88 \%$ erupted spontaneously, $10 \%$ did not return to the occlusal plane, and $2 \%$ failed to re-erupt due to ankylosis. ${ }^{15}$ The incomplete eruption or noneruption is especially true when the intrusion is associated with alveolar bone fracture, which may prevent the re-eruption movement as the tooth become ankylosed because of high friction between its root and bony fragment. ${ }^{16}$

In cases treated by repositioning and splinting also, ankylosis may follows and presents a secondary problem subsequently in terms of exfoliation. The complication is the result of damage to periodontal ligament which induces resorption followed by invasion and activity of osteoblast cells and bony apposition (replacement resorption). ${ }^{16}$

One of the major factors that may influence the choice and success of treatment is the time elapsed between trauma and seeking treatment. According to Saporowski et al (1994) early treatment of intruded teeth by repositioning and fixation relieves apical compression to the traumatized tooth, reducing the possibility of ischemia and favoring possible re-anastomoses, thus reducing the risk of pulp necrosis. ${ }^{9}$ Clinical studies in humans have shown small, insignificant
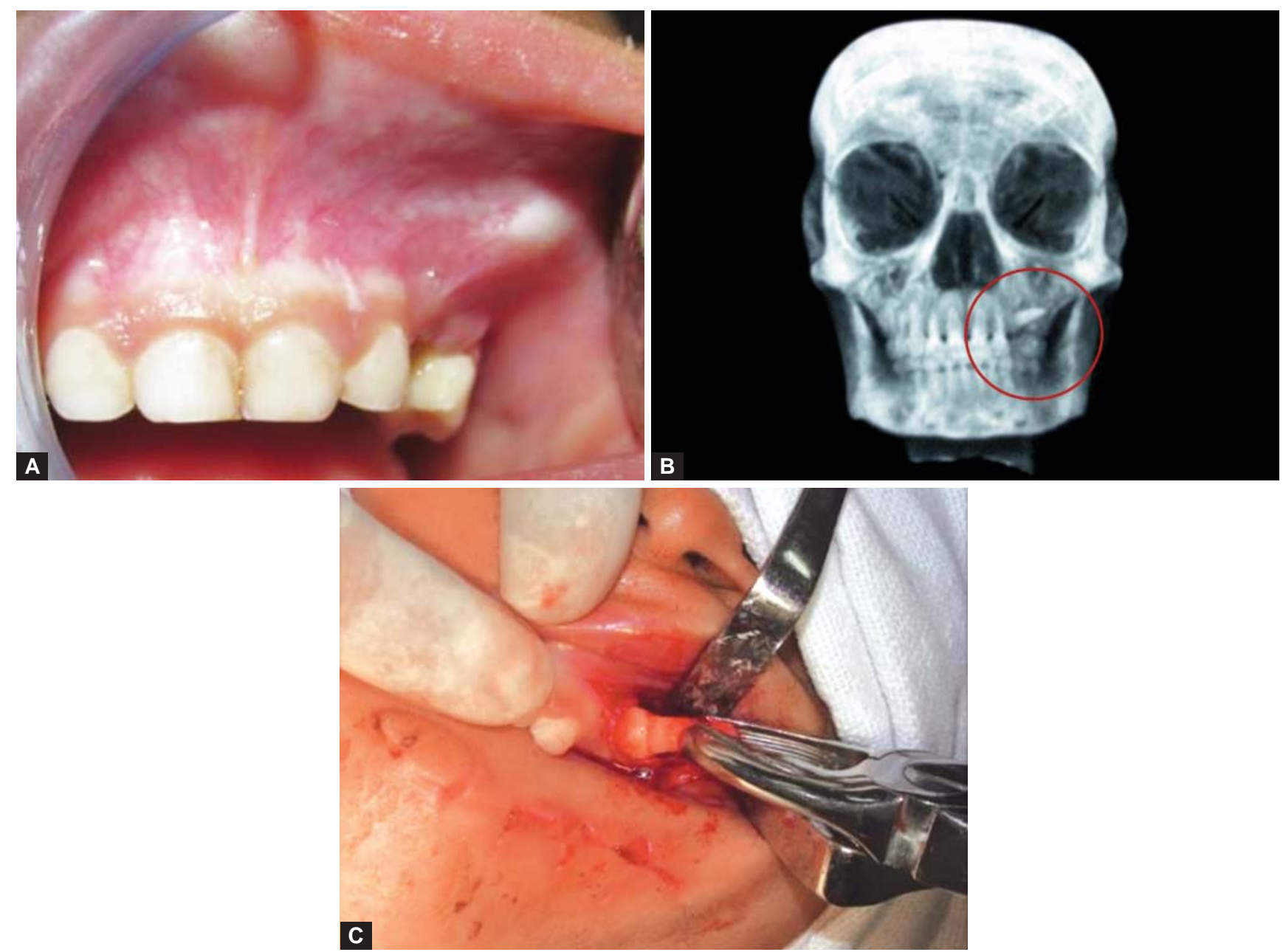

Figs 3A to C: (A) Intrusion of left maxillary primary canine with roots displaced palatally and (B) CT scan showing intruded canine with roots encroaching upon permanent tooth bud and $(C)$ extraction of canine under $\mathrm{GA}$ 
differences in relation to the extent and frequency of developmental disturbances in the permanent dentition when treatment with preservation and extraction were compared. ${ }^{17}$ Consequently, until further studies are conducted conservative therapy is the favored approach. Most authors agree that only teeth with facially displaced apices should be allowed to re-erupt. During the re-eruption phase of intruded primary teeth, the risk of acute inflammation, around the displaced tooth still exists with clinical presentation of swelling of the gingivae or parulis formation. ${ }^{16}$ Sometimes, in these cases, antibiotic therapy becomes essential to prevent the spread of inflammation and infection to the permanent tooth germ. ${ }^{17}$

According to American Academy of Pediatric Dentistry guidelines, if root gets displaced through labial plate, the tooth is left for spontaneous eruption. Re-eruption of the primary incisor is anticipated and normally occurs within a maximum of 6 months after the injury. If no signs of reeruption appear after 3 to 4 weeks of injury, the primary tooth should be extracted. In case the root is displaced palatally, extraction is indicated. ${ }^{18}$

\section{Management of Intruded Permanent teeth}

The severity of intrusion and treatment method used for an intruded permanent tooth, have been reported as important predictors of pulp necrosis and subsequent tooth survival. The strategy of treatment depends on the stage of root development, severity of intrusion, presence of alveolar fracture, single or multiple tooth/teeth intrusions, and must be focused on the elimination of postinjury complications. ${ }^{1}$ The possible treatment modalities could be:

Passive repositioning (PR), to allow the tooth to re-erupt. For long time, it has been known that intruded primary teeth usually re-erupt spontaneously; this may also take place in cases of intruded permanent teeth, especially in instances with immature root formation. ${ }^{7,19}$ Thus, a conservative management should always be tried as one of the treatment option.

Active repositioning of the tooth including immediate surgical repositioning $(\mathrm{SR})$ or orthodontic repositioning using removable or fixed appliances (OR).

The main advantage of surgically repositioning approach is that it will remove the bacteria contaminated crown surface from its position in the socket, the periradicular compression areas are released thereby osteoclast activity around the tooth may be reduced. ${ }^{7}$

The repositioning of tooth using an orthodontic appliance eliminates the trauma elicited by surgical repositioning. ${ }^{7}$

The International Association of Dental Traumatology (IADT) has developed a consensus statement regarding treatment of intruded teeth after a review of the dental literature and group discussions. ${ }^{8}$ The IADT recommendations regarding treatment of intruded teeth are as follows:

\section{Teeth with Incomplete Root Formation}

- Allow eruption without intervention

- If no movement of the intruded tooth occurs within a few weeks, initiate orthodontic repositioning

- If tooth is intruded more than $7 \mathrm{~mm}$, reposition surgically or orthodontically.

\section{Teeth with Complete Root Formation}

- Allow eruption without intervention if tooth intruded less than $3 \mathrm{~mm}$. If no movement is evident within 2 to 4 weeks, reposition it surgically or orthodontically to prevent ankylosis.

- If tooth is intruded beyond $7 \mathrm{~mm}$-reposition it surgically.

The pulp will generally becomes necrotic in teeth with complete root formation. Root canal therapy using a temporary filling with calcium hydroxide is recommended and treatment should begin 2 to 3 weeks after surgery.

Treatment recommendations for intruded incisors, as per UK National Clinical Guidelines, ${ }^{20}$ are summarized in Table 1.

Humphrey et al proposed that treatment methods can not be reliable predictors of clinical outcomes as the injury related variables, degree of intrusion and stage of apical development affect outcomes sufficiently to confound predictions. ${ }^{21}$ Andreasen et al in a prospective study of $140 \mathrm{intru-}$ ded permanent teeth concluded that in patients with intruded teeth with incomplete root formation, spontaneous eruption should be expected. In patients with complete root formation and with an age of 12 to 17 spontaneous eruption can still occur, but must be monitored very carefully. In older patients (i.e. $\geq 17$ years) with completed root formation, either surgical or orthodontic extrusion should be attempted as the latter appeared to lead to a slight reduction in the risk of complications however, the extent and direction of the intrusion may favor surgical repositioning. ${ }^{7}$

Table 1: Summary of treatment recommendations for intruded incisors as per UK National Clinical Guidelines

\begin{tabular}{lll}
\hline Degree of intrusion & $\begin{array}{l}\text { Incomplete root } \\
\text { development }\end{array}$ & $\begin{array}{l}\text { Complete root } \\
\text { development }\end{array}$ \\
\hline Mild $(<3 \mathrm{~mm})$ & $\mathrm{PR}$ & $\begin{array}{l}\text { PR and after } 2 \text { to } \\
3 \text { weeks OR ** }\end{array}$ \\
Moderate $(3-6 \mathrm{~mm})$ & $\mathrm{PR}^{*}$ & $\begin{array}{l}\text { SR or OR } \\
\text { S** }\end{array}$ \\
Severe $(>6 \mathrm{~mm})$ & $\mathrm{PR}^{*}$ & $\mathrm{SR}$ \\
\hline
\end{tabular}

*If passive repositioning PR not working within 2 to 3 weeks, start orthodontic repositioning OR; ${ }^{*}$ Passive repositioning (PR) in preference to orthodontic repositioning (OR), i.e. not personal preference. If PR not working within 3 weeks, start OR; ${ }^{* \star *} \mathrm{OR}$ and surgical repositioning (SR) both appropriate; however, SR often involves fewer visits 
Neto et al stated that management of intruded teeth with surgical repositioning was strongly related with alveolar bone loss in the short term course, but had little clinical significance on a long term basis. The watchful waiting for spontaneous re-eruption was associated with more chances of pulp necrosis however, the choice for this treatment strategy is based on the fact that allowing the tooth to return spontaneously to its preinjury state allows eruption to occur in a more physiological manner, cause less alveolar resorption and avoids performance of surgical procedure in a child already distressed by trauma. ${ }^{22}$

\section{Splinting of Repositioned Teeth}

Intruded tooth that has been repositioned surgically or orthodontically require appropriate splinting. A flexible splint for short duration should be used to stabilize the intruded tooth as well as allowing physiological tooth movement. While neither the specific type of splint nor the duration of splinting are significantly related to healing outcomes, it is considered best practice to maintain repositioned tooth in correct stabilized position for patient's comfort and improved function. ${ }^{23}$ The splinted tooth should be out of traumatic occlusion. Andreasen et al recommended splinting period of 6 to 8 weeks following repositioning surgically or orthodontically, ${ }^{7}$ however, a shorter period of 10 days also has been shown to permit sufficient reduction in mobility to allow function. ${ }^{21}$

\section{Follow-up}

Teeth with incomplete root development should be monitored closely with root canal treatment being indicated only following diagnosis of pulp necrosis. ${ }^{7}$

In teeth with complete root development in view of the very high risk of loss of pulpal vitality, root canal treatment is often indicated in cases of moderate to severe intrusion. There is also a high risk of root resorption in these teeth. The recommended time to start root canal treatment is approximately 2 weeks after the injury. In cases of severe intrusion, this early endodontic therapy is facilitated by rapid surgical repositioning. In the presence of inflammatory root resorption, the canal should be dressed with nonsetting calcium hydroxide paste with appropriate replacement until root resorption is controlled before obturation. ${ }^{20}$

\section{Prognosis}

Intrusive luxation in permanent teeth has been associated with favorable and unfavorable outcomes. Favorable outcomes include tooth in place, erupting, intact lamina dura, no signs of resorption and continuing root development in immature teeth. Also severe complications may be seen especially pulp necrosis, external root resorption, and mar- ginal bone loss. Parents and patients should be informed of the range of clinical outcomes associated with intrusive luxation. ${ }^{8}$ A number of preinjury and injury factors have significant influence on the healing outcome. The most prominent factor considered is the stage of root development as less risk of complications are associated with immature root formation possibly because of softer bone surrounding teeth with immature root development, which may allow intrusion with less trauma to the periodontal ligament. Also, the extent of intrusion has been found to have strong influence as more complications have been associated with intrusion more than $7 \mathrm{~mm}^{24}$

\section{Treated Cases of Intrusive Injuries at OHSC, PGIMER}

Some of the cases of intrusive injuries reported and treated at the Oral Health Sciences Centre are detailed as under:

\section{CASE REPORTS}

\section{Case 1}

A 16 years old female child reported to the unit of pediatric dentistry at Oral Health Sciences Centre with the chief complaint of pain and swelling on lips and increased mobility of upper and lower anterior teeth. The child had a history of trauma to lips and teeth due to fall from 2 to 3 days before her visit. She had a history of bleeding from mouth and chin. She had been referred from Government Hospital, Uttarkashi, after having received first aid therapy and sutures on chin. The girl's medical history was noncontributory. Extraoral examination revealed sutured lacerations on chin (Fig. 4A) with swelling and laceration on lower lip (Fig. 4B).

The intraoral examination revealed lacerations on lower lip mucosa and mobility of dento alveolar segment between permanent mandibular right lateral incisor (42) and left lateral incisor (32). Permanent maxillary left central (21) and lateral incisors (22) were intruded and lateral luxation of permanent maxillary right central (11) and lateral incisors (12) was evident clinically (Fig. 4C). The radiographic examination revealed that the permanent maxillary left central and lateral incisors were severely intruded with concomitant uncomplicated enamel fracture. Both the permanent maxillary central and lateral incisors' roots were matured with almost closed apices. The periodontal spaces around the intruded teeth were diminished, but radiographic examination did not reveal any horizontal root and supporting tissue fracture (Fig. 4D).

No other specific findings and neurological disorders were found. The girl had no pain, but was very upset and disinclined to the treatment which was an indication of the psychological impact because of trauma. 


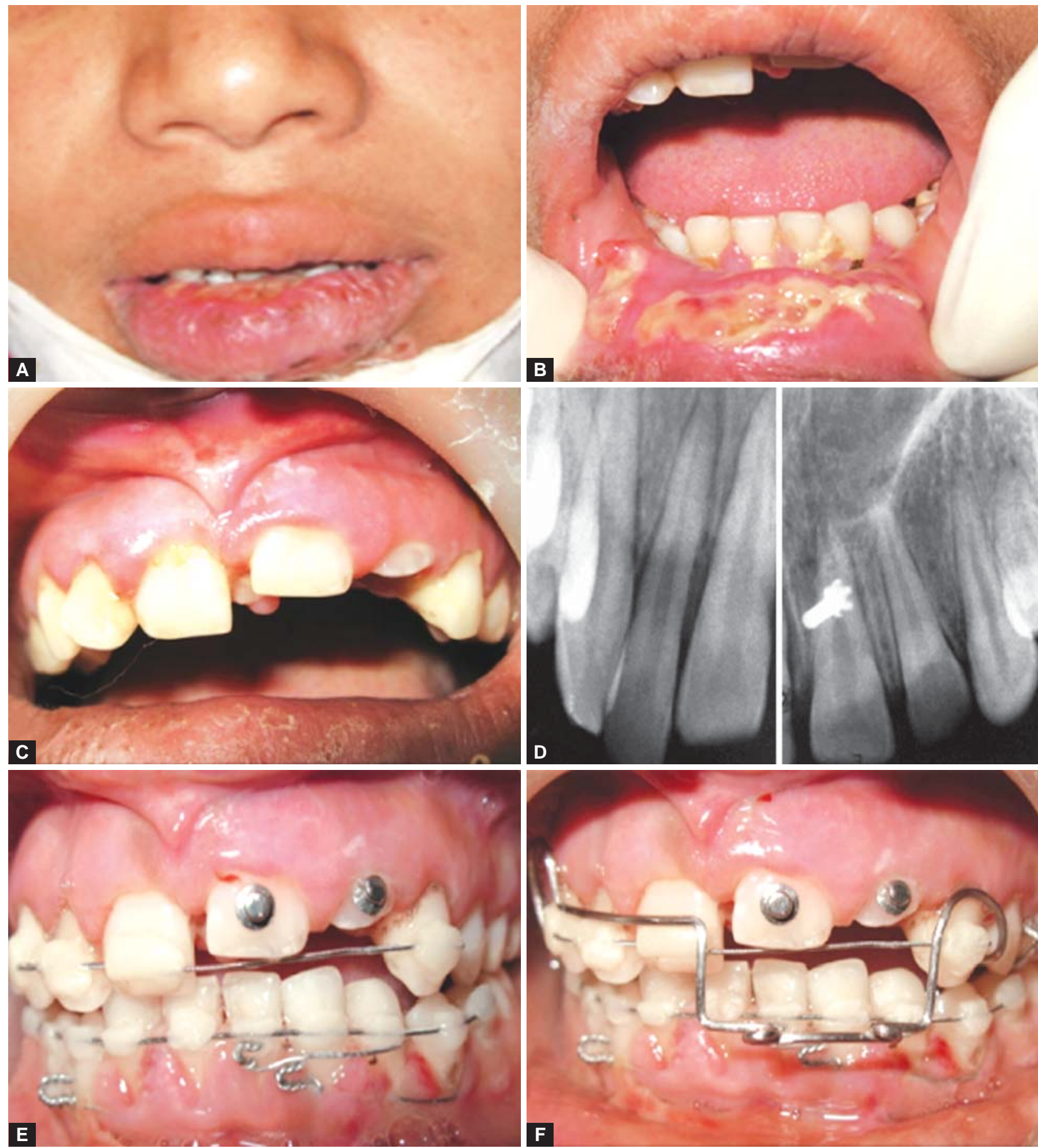

Figs 4A to F: Case 1: (A) extraoral view of the 16 years old female patient with lacerations on chin, $(B)$ intraoral photograph showing lacerations on lower lip mucosa, (C) intraoral photograph showing intrusion of maxillary incisors, (D) periapical radiograph showing intrusion of incisors with no sign of root fracture. Note the diminished periodontal space around the intruded teeth, (E) splinting of maxillary and mandibular mobile teeth and attachments of lingual buttons on 21,22 and (F) placement of Hawley's appliance with modified labial bow

After all the treatment options were considered, orthodontic extrusion of the teeth was considered due to the severity of intrusion and keeping in mind the stage of root development of the affected teeth. The normal overjet, overbite, and class I molar relationship with normal profile represented no contraindication for the planned procedure.

Composite and multiflex wire splinting was done from right maxillary canine (13) to left maxillary first premolar (24) except intruded left maxillary central (21) and lateral incisor (22). Interdental splinting was done from left mandibular lateral incisor (32) to right mandibular lateral incisor (42) followed by composite and multiflex wire splinting from left mandibular first premolar (34) to right mandibular first premolar (44). Lingual buttons were bonded on labial surface of 21, 22 (Fig. 4E).

Hawley's appliance with modified labial bow (with loops) was fabricated and the application of force with elastics was applied for the extruded 21, 22 (Fig. 4F) 

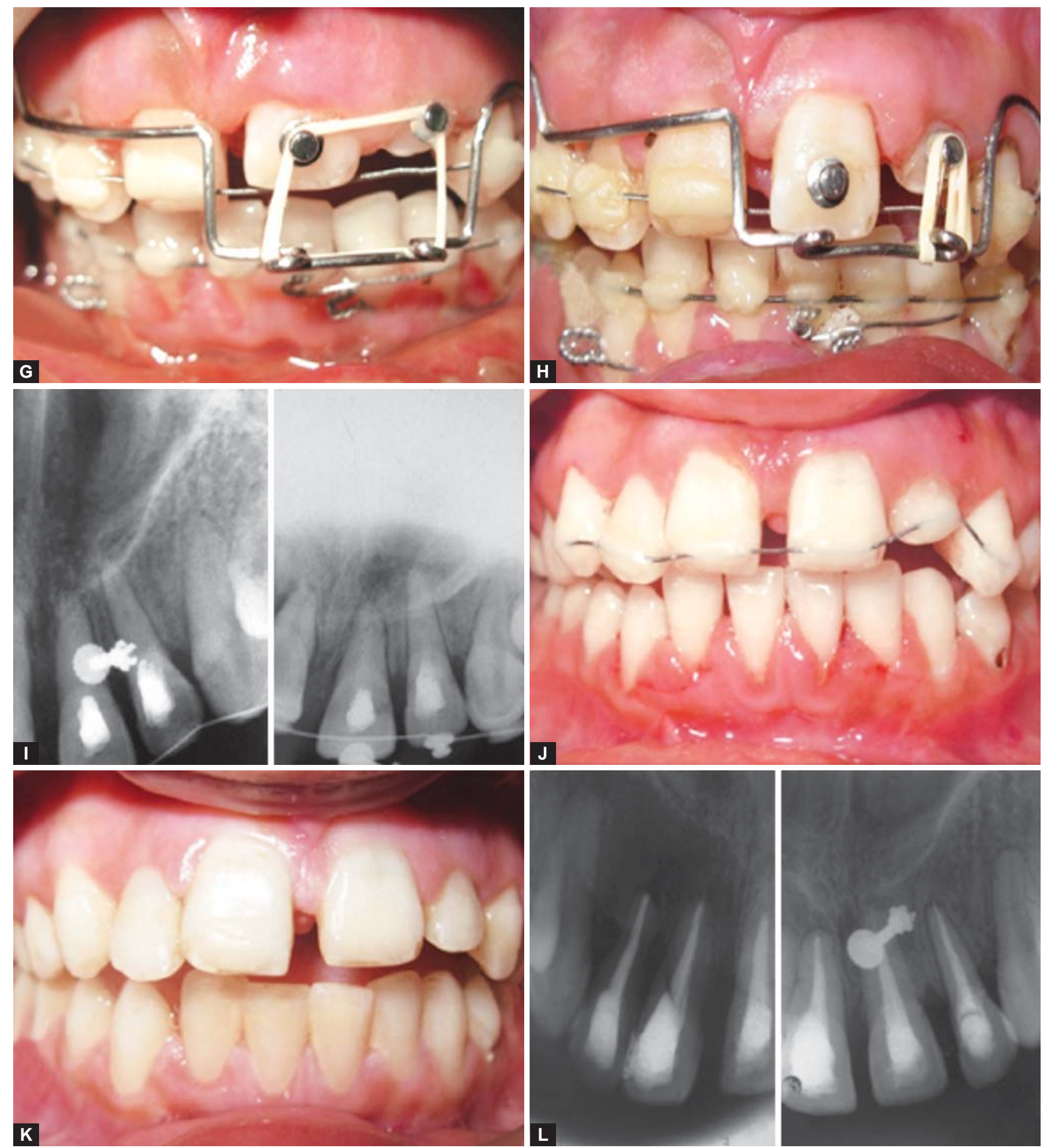

Figs 4G to L: (G) Use of $3 / 16$ inches elastics for extrusion of intruded teeth, $(H)$ complete extrusion of 21 and partial extrusion of 22 noted, (I) periapical radiograph showing calcium hydroxide in the canals, (J) splinting of extruded teeth with flexible splint for 6 weeks and $(\mathrm{K}$ and $\mathrm{L})$ clinical and radiographic aspects after 12 months

3/16 inches elastics were used for extrusion which were to be changed every day (Fig. 4G) and the patient as well as her parents were instructed on the importance of plaque control using chemical and mechanical methods and diet advice. The intruded teeth were diagnosed as having pulp necrosis and endodontic treatment was initiated. The root canal of 11,12 , 21, 22 was extirpated, instrumented and biomechanically prepared. After drying with sterile paper points, the canal was filled with calcium hydroxide paste and the coronal cavity of the tooth was sealed with zinc oxide-eugenol cement. The extrusion of central incisor to its preinjury state was achieved in 4 weeks time, however, lateral incisor was seen to have partial extrusion (Fig. 4H). The flexible splint was placed for 6 weeks after the extrusion and the calcium hydroxide dressing was changed. The intracanal dressing was maintained for 3 months. (Figs 4I and J) After the third month, root canal obturation was performed in a conventional manner, avoiding excessive forces, and the affected 

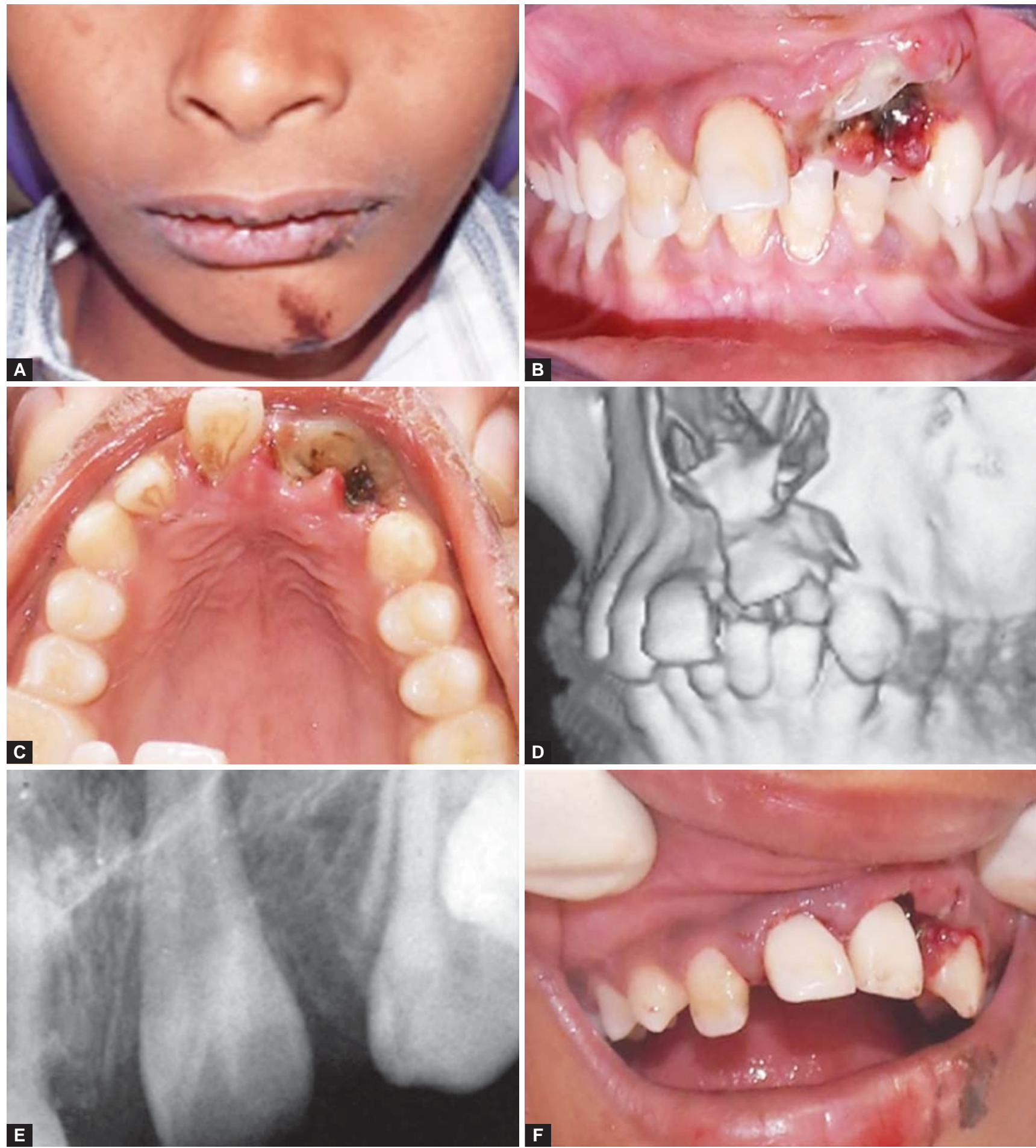

Figs 5A to F: Case 2: (A) extraoral view of the child showing lacerations on the chin and lip, $(B$ and $C)$ intraoral view showing severely intruded left maxillary central incisor (21) and clinically missing left maxillary lateral incisor(22), (D) CT scan showing intruded left maxillary incisor with alveolar fracture, (E) periapical radiograph showing intruded left maxillary central incisor (21) and absence of left maxillary lateral incisor (22) and (F) intraoral view after surgical repositioning of intruded central incisor to its original position

the teeth were restored with light-cured hybrid composite resin. Radiographic examinations and clinical examinations (including assessment of tooth color, mobility, percussion sensitivity and tone, gingival pocket depth, peri apical tenderness and trauma from occlusion) were performed at the regular intervals. Follow-up after 1 year presented with uneventful healing (Figs 4K and L).

\section{Case 2}

A 12 years old boy reported to the department with facial trauma due to road traffic accident. There was no history of loss of consciousness or vomiting and no significant medical history was reported. First aid management was done in the advanced trauma ward of the institute and patient was referred to the unit of pediatric dentistry for further treat- 

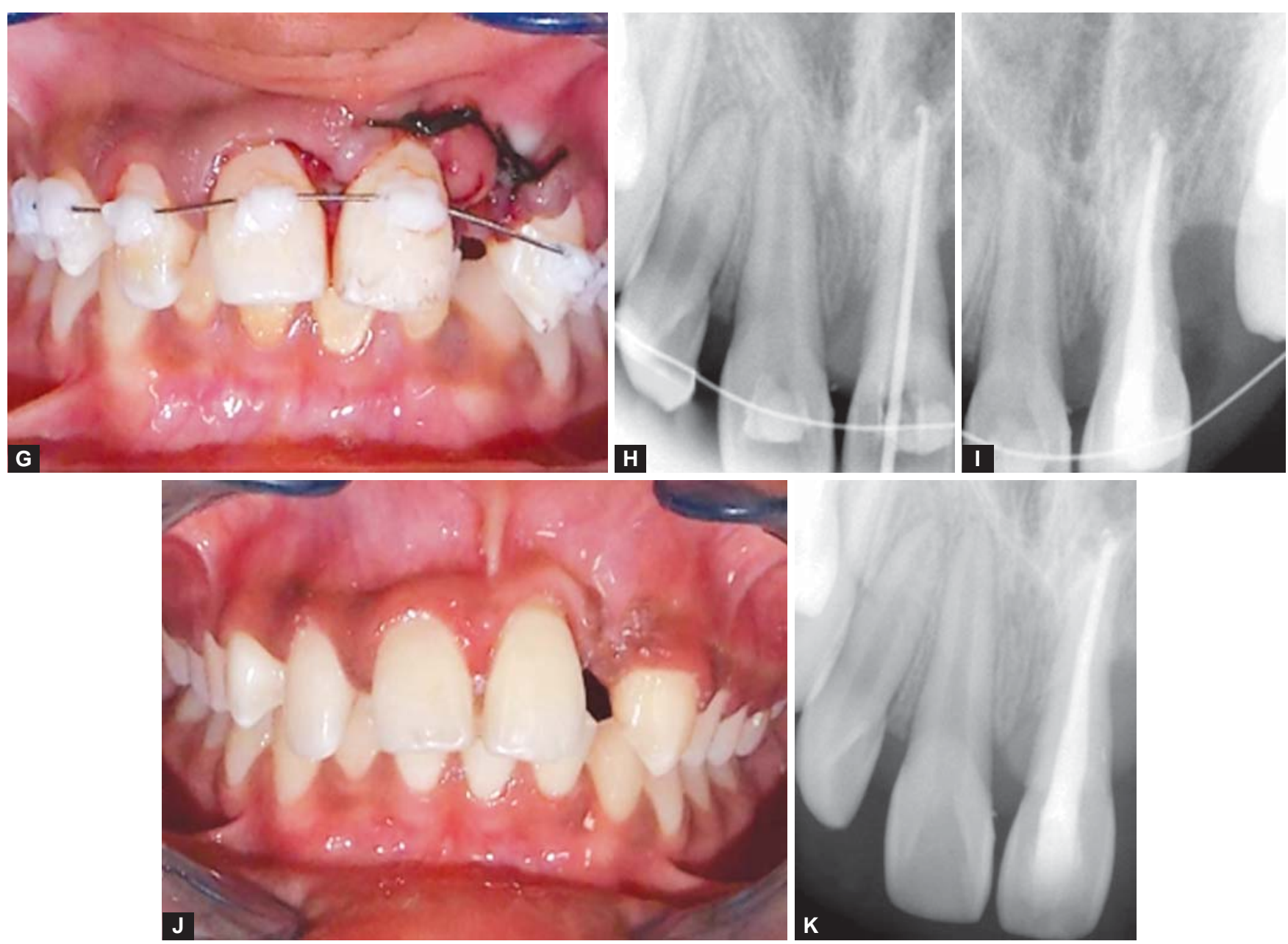

Figs 5G to K: $(G)$ Splinting of repositioned incisor using flexible splint, $(H$ and $I)$ periapical radiographs showing endodontic treatment of 21 and $(\mathrm{J}$ and $\mathrm{K}$ ) clinical and radiographic aspects after 18 months

ment. Extraoral examination revealed lacerations on chin with swelling and laceration on lower lip (Fig. 5A).

The intraoral examination revealed lacerations on lower lip mucosa. Permanent maxillary left central incisor (21) was severely intruded (more than $7 \mathrm{~cm}$ ) maxillary left lateral incisor (22) was clinically missing and right maxillary central incisor (11) was luxated (Figs 5B and C). The radiographic examination revealed that the permanent maxillary left central incisor (21) was severely intruded with concomitant uncomplicated enamel fracture and the root formation was almost complete. The periodontal space around the intruded teeth was diminished, but radiographic examination did not reveal any horizontal root and supporting tissue fracture. The radiographic examination revealed missing maxillary left lateral incisor (Figs 5D and E). Final diagnosis of avulsion of left lateral incisor and intrusion of left central incisor was made.

No other specific findings and neurological disorders were evident. After all the treatment options were considered, surgical repositioning of the teeth was considered due to the severity of intrusion and stage of root development of the affected teeth. The normal overjet, overbite, and class I molar relationship with normal facial profile represented no contraindication for the planned procedure. After anesthetizing the region, the tooth was carefully luxated with elevators and forceps avoiding excessive forces. Once it was mobile, the intruded tooth was brought into its original position with forceps (Fig. 5F). The root was never made to leave the alveolus, and care was taken to prevent inadvertently touching the root surface. After the tooth was splinted using multiflex wire and light-cured composite resin, occlusal adjustment was maid (Fig. 5G). Antibiotic therapy was prescribed for 3 days and the patient and his parents were instructed on the importance of plaque control using chemical and mechanical methods. One week after splinting, endodontic treatment was initiated (Fig. 5H). The root canal was extirpated, instrumented and biomechanical preparation was done. After drying, the canal was filled with calcium hydroxide paste and the coronal cavity of the tooth was sealed with zinc oxide-eugenol cement. Three weeks after the extrusion, the splint was removed. After 2 months of calcium hydroxide dressing, root canal obturation was performed in a conventional manner, avoiding excessive forces and permanent maxillary central incisor was restored 
with light-cured hybrid composite resin (Fig. 5I). Eighteen months follow-up of the case revealed uneventful healing (Figs 5J and $\mathrm{K}$ ).

\section{REFERENCES}

1. Lee J, Divaris K. Hidden consequences of dental trauma: the social and psychological effect. Pediatr Dent 2009;31:96-101.

2. Glendor U. Epidemiology of traumatic dental injuries: a 12 years review of the literature. Dent Traumatol 2008;24:603-611.

3. Andreasen JO, Andreasen FM, Andersson L. Textbook and coloratlas of traumatic injuries to the teeth. 4th ed. Oxford UK Wiley-Blackwell; 2007.

4. Bastone EB, Freer TJ, McNamara JR. Epidemiology of dental trauma: a review of the literature. Aust Dent J 2000;45:2-9.

5. Daib M, Elbadrawy HE. Intrusion injuries of primary incisors. Part 1: review and management. Quintessence Int 2000;31: 327-334.

6. Andreasen JO, Bakland LK, Matras RC, Andreasen FM. Traumatic intrusion of permanent teeth. Part 1.An epidemiological study of 216 intruded permanent teeth. Dent Traumatol 2006;22:83-89.

7. Andreasen JO, Bakland LK, Andreasen FM. Traumatic intrusion of permanent teeth. Part 3. A clinical study of the effect of treatment variables such as treatment delay, method of repositioning, type of splint, length of splinting and antibiotics on 140 teeth. Dent Traumatol 2006;22:99-111.

8. DiAngelis AJ, Andreasen JO, Ebeleseder KA, et al. International Association of Dental Traumatology guidelines for the management of traumatic dental injuries: 1. Fractures and luxations of permanent teeth. Dent Traumatol 2012;28:2-12.

9. Soporowski NJ, Allred EN, Needleman HL. Luxation injuries of primary anterior teeth-prognosis and related correlates. Pediatr Dent 1994;16:96-101.

10. Rakocz M, Keating J, Croll TP. Traumatic impaction of a maxillary primary incisor into the nasal cavity. J Pedod 1985;9: 338-343.

11. Carvalho V, Ribeiro J, Campos V. Frequency of intrusive luxation in deciduous teeth and its effects. Dent Traumatol 2010;26: 304-307.

12. Malmgren B, Andreasen JO, Flores MT, et al. International Association of Dental traumatology guidelines for management of traumatic dental injuries: 3 Injuries in the primary dentition. Dent Traumato 2012;28:174-182.

13. Colak I, Markovic D, Petrovic B, Peric T, Milenkovic A. A retrospective study of intrusive injuries in primary dentition. Dent Traumatol 2009 Dec;25(6):605-610.

14. Ravn JJ. Developmental disturbances in permanent teeth after intrusion of their primary predecessors. Scand J Dent Res 1976; 84:137-141.

15. Holan G, Ram D. Sequelae and prognosis of intruded primary uncisiors: a retrospective study Pediatr Dent 1999;21:242-247.

16. Daib M, Elbadrawy HE. Intrusion injuries of primary incisors. Part II: Sequelae affecting the intruded primary incisor. Quintessence Int 2000;31:335-341.

17. Daib M, Elbadrawy HE. Intrusion injuries of primary incisors. Part III: Effect on the permanent successor. Quintessence Int 2000;31:377-384.

18. American Academy of Pediatric Dentistry. Guidelines on management of acute dental trauma. Pediatric Dentistry Reference Manual 2012-13;34:230-238.

19. Jacobsen I. Clinical follow-up study of permanent incisors with intrusive luxation after acute trauma. J Dent Res 1983;62:486.

20. Albadri S, Zaitoun H, Kinirons M. UK National clinical guidelines in pediatric dentistry. Treatment of traumatically intruded permanent incisor teeth in children. Int J Pediatr Dent 2010;20(Suppl 1)7:1-4.

21. Humphrey JM, Kenny DJ, Barrett EJ. Clinical outcomes for permanent incisor luxations in a pediatric population. I. Intrusions. Dent Traumatol 2003;19:266-273.

22. Neto JJSM, Gondim JO, Carvalho FM, Giro EMA. Longitudinal clinical and radiographic evaluation of severely intruded permanent incisors in a pediatric population. Dent Traumatol 2009;25:510-514.

23. Kahler B, Heithersay GS. An evidence: based appraisal of splinting luxated, avulsed and root-fractured teeth. Dent Traumatol 2008;241:2-10.

24. Andreasen JO, Bakland LK, Andreasen FM. Traumatic intrusion of permanent teeth. Part 2. A clinical study of the effect of preinjury and injury factors such as sex, age, stage of root development, tooth location and extent of injury including number of intruded teeth on 140 intruded permanent teeth. Dent Traumatol 2006;22:90-98. 